\title{
Towards an Ontological Learners' Modelling Approach for Personalised E-Learning
}

\author{
http://dx.doi.org/10.3991/ijet.v8i2.2476
}

\author{
Seyed Ali Hosseini ${ }^{1}$, Abdel-Rahman H. Tawil ${ }^{2}$, Hossein Jahankhani ${ }^{2}$, Maryam Yarandi ${ }^{2}$ \\ ${ }^{1}$ King's College London, London, UK \\ ${ }^{2}$ University of East London, London, UK
}

\begin{abstract}
The rapid advancements in the semantic web technologies has enabled personalised learning based on learner's characteristics in the learning process. We have implemented a Personalised Adaptive e-Learning system (onto-PAdeL) which uses an ontological approach in designing learners' models. Thus, this paper focuses on describing our approach for modelling learners based on their characteristics such as abilities, learning style(s), prior knowledge and preferences. The system uses Item Response Theory (IRT) for calculating learner's abilities. The learning style can be represented according to different theories, each of which supports personalisation in different ways. We show that using ontologies for learner modelling, in addition to many different benefits, enables reasoning for adaptive learning.
\end{abstract}

Index Terms-e-Learning, ontology, personalisation, learner model

\section{INTRODUCTION}

Developments in web technology offer new opportunities in the field of e-Learning. However, most current e-learning systems are based on a one-size-fitsall approach in content delivery. Adaptively and personalisation in learning are techniques recently studied in order to overcome this problem (Surjono, 2011). Personalisation is a critical requirement for elearning systems which use the full potential of web technologies, dynamically adapting learning content to learner's educational needs for promoting learning results (Jeong, Choi, \& Song, 2012). However, such personalised services are not often implemented properly in most cases, as they have a different attitude on which features should be used and how these features are used.

In personalised e-learning systems, all learners have a profile in the learner model. The model contains knowledge about the learner to enable the predication of his/her behaviour through a personalised learning system and based on his/her characteristics, thus offering an appropriate learning path. In fact, learner model describes learner's characteristics such as personal identification (name, family, age, job), education, demands, preferences, learner's experiences, existing knowledge and abilities (Baylari \& Montazer, 2009; Lu, 2008). E-Learning systems generate better learning tasks by using the information captured in the learner model. The model is continuously updated during the learning process, hence, resulting in a more accurate personalisation and interactivity for individual learners.
Semantic web allows data to be read, processed and understood by machines precisely and intelligently. Ontology is the most suitable means for representing knowledge due to its flexibility and extensibility in designing concepts and their relationships. It is a formal, explicit specification of a conceptualisation (Gruber, 1993) that represents a conceptual understanding of specific learners due to identifying appropriate items and relationships for a set of knowledge in a specific domain. Furthermore, they enable people and applications to share common understanding of knowledge structures suitable in e-learning systems. In this paper, ontologies are used to describe learner's characteristics through modelling concepts and relationships in a higher level of abstraction.

We consider the learner model as one of the most important elements in personalisation for an educational environment. Therefore, this paper proposes the use of ontologies in learners' model for describing their profile. The learner's model is initialised during user registration and it is updated during the learning process. In our approach, learner's abilities are estimated based on the Item Response Theory.

The paper is organized as follows. In section 2 some related approaches are described. Details about learner modelling in Onto-PAdel are presented in Section 3. Section 4 presents estimation of learner's abilities. Ontology-based personalisation is explained in section 5 and Section 6 brings the conclusions.

\section{RELATED WORK}

Learner's model contains learner's characteristics which are essential for adaptive learning. A typical learner model includes most important features of the learner that affects his/her learning, such as current knowledge, background, interest, goals, learning style and preferences (Bunt \& Conati, 2003; Conati, Gertner, \& Vanlehn, 2002; Díaz \& Gervás, 2005; Gauch, Speretta, Chandramouli, \& Micarelli, 2007). A flexible approach in student modelling is presented in (Jeremic', Jovanovic', \& b, 2012). This user model is used in DEPTHS (Design Pattern Teaching Help System), which is an intelligent tutoring system for learning software design patterns. DEPTHS makes use of a knowledge assessment method based on fuzzy rules to update students' models during the learning process.

Recent developments in semantic web technologies have informed research on applying these technologies for developing adaptive e-learning systems. Several attempts have been made to implement ontology-based educational systems, one of the most important components in these systems is the learner model (Henze, Dolog, \& Nejdl, 2004; Jovanović, Gašević, \& Devedžić, 2009; Winter, Brooks, \& 
PAPER

TOWARds An Ontological LEARners’ MODELling APPROACH FOR PERSONALISED E-LEARNING

Greer, 2005). Some of these researches focus on proposing ontology-based approach for sharing student profiles between different learning systems(Brusilovsky, Sosnovsky, \& Yudelson, 2005; Dolog \& Schäfer, 2005). For instance, ADAPT ${ }^{2}$ (Brusilovsky et al., 2005) is an Advanced Distributed Architecture for Personalized Teaching \& Training. It employs a high-level mechanism for enabling interoperability between ontology-based user models in adaptive Web-based systems. The main idea of the $\mathrm{ADAPT}^{2}$ approach is the use of an Ontology Server to exchange user models. The ontology server seems like the most appropriate place to store a user model in this system. Moreover, some researchers attempt to propose the usage of ontologies and rule-based methods for developing learner models. For example, a rule-based solution for developing the user profile in an e-learning system is presented in (Brut, Asandului, \& Grigora, 2009). In the proposed solution, a two layers user model (competences and interests) is designed through ontological constructs. The user model provides personalised functionalities, especially with recommendations on potential collaborators for the users of an e-learning system. Correspondingly, (Vesin, Ivanović, Klašnja-Milićević, \& Budimac, 2011) proposed the usage of ontologies and rule languages for building learner model in Java tutoring system. This approach is used for implementing adaptation in web-based PRogramming TUtoring System (Protus) where the learner model is updated as a result of firing the semantic rules.

An ontology-based learner model expresses the learner's characteristics in an abstract way. But, it only expresses learner's characteristics which is essential to support the system's needs. For example, (Baishuang \& Wei, 2009) proposed a learner model for adaptive learning system based on Semantic Web. This learner model mainly includes study style, cognition level, interest and hobby. The authors used Solomon Study Style to obtain learner's learning style. The learner model ontology is defined using protégé ${ }^{1}$ and it is updated through mining historical data. While, (Liu, Liu, Kang, Zhong, \& Jia, 2009) proposed an ontologybased learner model to describe five aspects of learner's characteristics namely learner's basic information, prior knowledge level, preference, cognitive skills, and performance. The authors calculate semantic similarities between learner's model ontology and knowledge base ontology to recommend effective learning resources based on learner's needs.

Most of the aforementioned systems concentrate on some learner's characteristics in providing adaptive functionality such as learner preferences or knowledge. However, learner's ability as an effective factor for implementing adaptation mechanisms is mostly neglected in modelling learners. Besides, those systems do not support the usage of different learning style models (e.g. Kolb, VARK and Felder-Silverman) that improves the flexibility of learner model. Structure of learner model ontology supporting the personalisation process is described in this paper. Moreover, to obtain more precise estimation of learner's ability, the results of learner's responses to the assignments are analysed according to Item Response Theory.

\section{LEARNER MODELLING}

We argue that in order to provide personalisation in elearning systems, it is necessary to store the learner's characteristics (e.g. abilities, preferences, prior knowledge, and learning style) in the learner model. Some of these characteristics are static whereas others are dynamic. Static features are initialised in the registration period, and they usually remain unchanged throughout the learning process such characteristics are learner's email, preferences, etc. On the other hand, dynamic features are updated during learning process based on the interaction of learner with the system, for example, learner's scores, abilities and knowledge. Learner modelling allows the system to personalise the interaction between the learner and learned content. To achieve this goal, the system should predict the needs of the learner based on the information in the learning model in order to then offer the content in a way that the learner can understand. There are several techniques for modelling the learner and refining this model. Ontologies have been proven to be an effective means for presenting knowledge within a specific domain in a semantic way (Snae \& Brueckner, 2007). Consequently, we propose an approach where an ontological model is used to present the learner's characteristics. This model is described in the following.

\section{A. Learner Model ontology}

The learner model ontology presents personal preferences and learning characteristic of the learner which has interaction with the system. The information is updated according to the learner's interactions with the content. The updated information is used by the adaptation model to make adaptation decisions. Fig 1 depicts the graphical representation of the user model. The information is available for the system to adapt the learning content presentation and navigation for the learner.

The top class of the learner model ontology is the User class, which is a superclass to PersonalInformation. The PersonalInformation class has metadata to present the basic individual information such as user's name, gender, email, etc. so that the system can identify the user. A subclass of the User class is the Learner class, which represents details about learners. The Learner class is a central concept as it includes all the properties of a learner (Yarandi, Tawil, \& Jahankhani, 2012). Comprising of learner's ability, preference, prior knowledge, feedback and learning style, these five classes are related to association through hasAbility, hasPreferences, hasPriorKnowledge, writeFeedback and hasLearningStyle properties. These aspects are considered important to describe the learning characteristics of the learner.

The Ability class presents the ability of the learner in each learning level. In order to estimate learner's ability, some regular exams are taken from the learner at different steps of the learning process. The results of these exams are analysed according to Item response Theory to obtain the learner's abilities. Explicitly, the ability level and the date when the abilities recorded are presented via abilityLevel and RecordedDate properties. The learner's abilities in

${ }^{1}$ http://protege.stanford.edu/ 


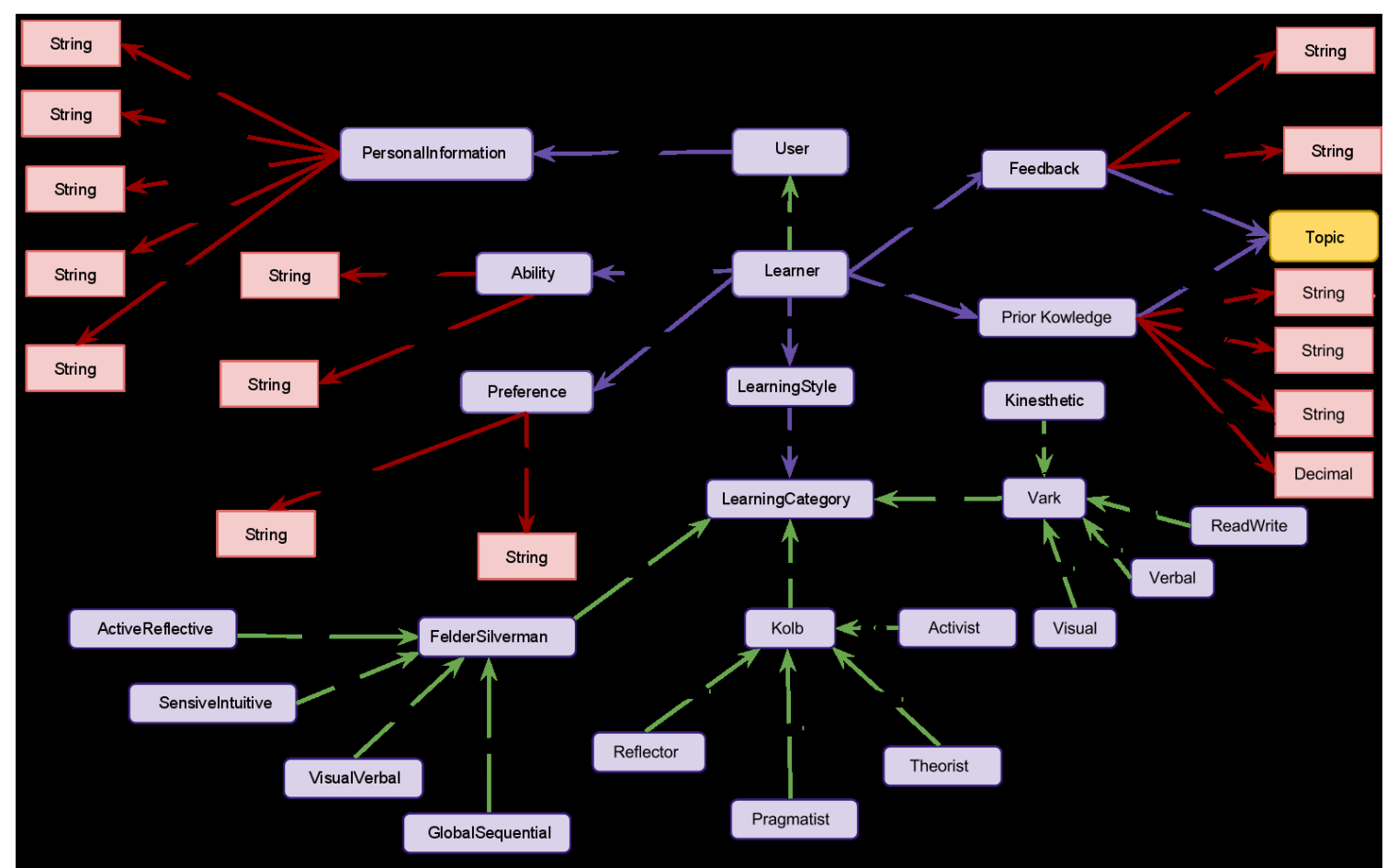

Figure 1. The graphical representation of the user model

different stages of the learning process are kept in the instances of Ability class to obtain the fluctuation of ability during the learning process. The following examples show two instances of the Ability class in OWL/XML syntax. It shows that the learner's ability was Moderate in 6th of April 2012 and is changed to High in 7 th of June 2012.

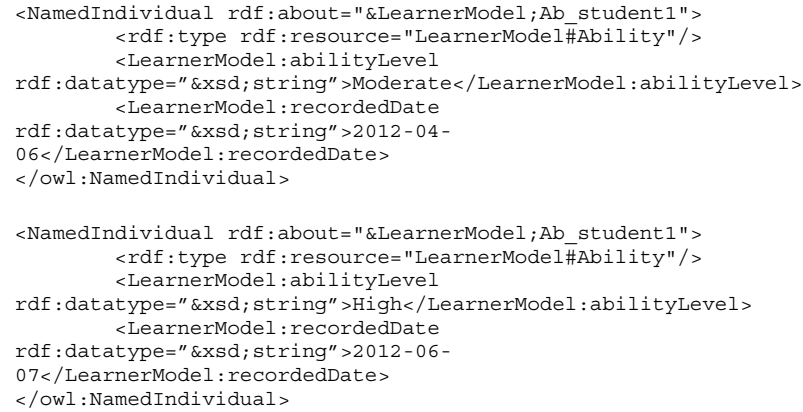

The Preferences class keeps learners' preferences with regards to colour, and language. These two features are used to provide adaptive presentation. An instance of Preferences class is shown in the following example:

<owl : Namedindividual

rdf : about =" =" \&UserModel ; Preferences_student 1 " >

$<$ rdf:type rdf:resource="\&UserModel; Preferences" / > $<$ UserModel: hasLanguagePreference

rdf : resource = "\&UserModel; Engl ish" / >

$<$ UserModel: hasColourPreference

rdf : resource = "\&UserModel; Green" / >

$</$ owl : NamedIndividual>

The example show that the language preference of student1 is "English" and also it shows that his/her colour preference is "Green".

Furthermore, each learner is also attached a set of prior knowledge related data which is presented in PriorKnowledge class via hasPriorKnowledge property. This class contains information about the learner's background knowledge and gained knowledge from previous steps of the learning process via this system. Gained knowledge can be obtained as a result of technical tests which are taken from individual learners. PriorKnowledge class has following data properties for recording the learner's knowledge:

1. The relatedTopic property refers to the topic of domain ontology that describe the topic of learner's acquired knowledge .

2. The priorKnowledgeValue property represents the percentage score which is calculated based on the learner's response to a presented test.

3. The recordedDate property keeps the date when the learner completed a test.

4. The testId property refers to the identification of completed test by the learner. If the learner needs to repeat a topic, this property prevent from presenting the same test repeatedly.

5. The activityLevel property represents the level of activities about this topic (e.g. Low, Moderate, High) to which the learner responds correctly.

The instance of this class can be taken as measures of a learner's prior knowledge. The example of learner's prior knowledge can look as follows.

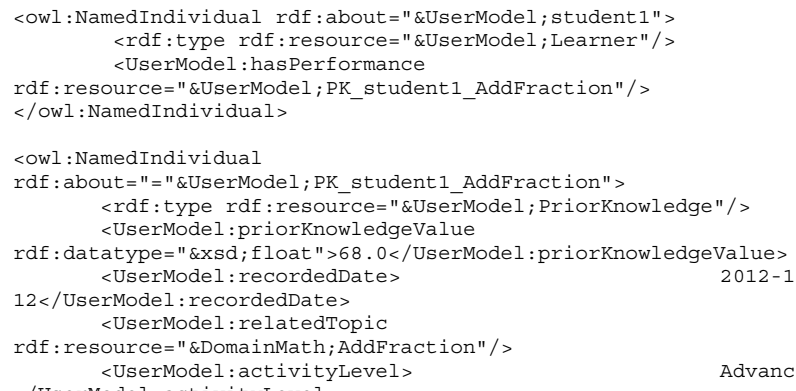


PAPER

The PK student1 AddFraction is an instance of PriorKnowledge class which keeps the Prior Knowledge of leaner student1 about "add fraction" topic.

Moreover, the learner's feedback is recorded in the Feedback class via writeFeedback Property. This class is associated with three following properties to represent the learner's feedback:

1. The relatedTopic property refers to a topic, which the feedback is about.

2. The note property represents feedback of learner about the mentioned topic.

3. The recordedDate keeps the date when the feedback is recorded.

Finally, the learningStyle class holds information about the learner's learning style (hasLearningStyle) is associated with the LearningStyleCategory class. There are different models about the learning style of learners learning methods. LearningStyleCategory class represents these different learning models namely Kolb (Kolb, 1984), Felder-Silverman(Felder \& Silverman, 1988) and VARK learning model (Fleming \& Mills, 1992).

Kolb's learning theory organises the following four distinct learning styles:

- Activist (Accommodator): Applying course material in new situations to solve real problems. Activists are good with complexity and are able to see relationships among aspects of a system.

- Theorist (Assimilator): This type of learner prefers information that is presented in an organised way and likes to have time for reflection. They learn with abstract ideas, create conceptual models, design experiments and analyse quantified information. They will carefully follow prepared exercises.

- Pragmatist (Converger): Converger learners are skilled at solving problems, making decisions and putting ideas into practice. They like to work actively on well-defined tasks. They prefer to deal with technical tasks and problems rather than with social and interpersonal discussions. They like interactive instruction, not passive.

- Reflector (Diverger): They respond well to explanations of how course materials relate to their experience interest and future careers. They understand the experience through concrete experience and transform it through reflective observation. They prefer to have information presented to them in a detailed, systematic, reasoned manner.

Honey \& Mumford (Honey \& Mumford, 1986) developed Learning Styles Questionnaire (LSQ), which is directly derived from Kolb's theory. Learners generally prefer one of the four styles above the others. The learner's learning preference is determined based on the result of the questionnaire. It is represented in Kolb class, which is defined as a subclass of the LearningStyleCategory class.

The Felder-Silverman model rates the learner's learning style in a scale of four dimensions. The learning style of each learner is determined through the result of a questionnaire which is developed in 1991 by Richard Felder and Barbara Soloman (Felder \& Soloman, 1991).
This questionnaire consists of 44 questions that classify a learning style across the following dimensions:

- Active and Reflective: Active learners tend to retain and understand information best by doing something active with it, i.e. discussing or applying it or explaining it to others. Reflective learners prefer to think about it quietly first. They may be more interested in reviewing other learners' and professional opinions rather than doing real activities.

- Sensing and Intuitive: Sensing learners tend to be patient with details and good at learning facts and doing laboratory work. For example, sensing learners will be interested in additional materials. Although, intuitive learners often prefer discovering possibilities and relationships. They prefer to learn abstractions and mathematical formulations. Sensors often like solving problems by well-established methods and dislike complications and surprises. Intuitive learners like innovation and dislike repetition.

- Visual and Verbal: Visual learners remember best when they see pictures, diagrams, flow charts, time lines, films, and demonstrations (Klasnja-Milicevic, Vesin, Ivanovic, \& Budimac, 2010). Verbal learners appreciate words, either written or spoken explanations.

- Sequential and Global: Sequential learners tend to gain understanding in linear steps, with each step following logically from the previous one. They like to follow logical stepwise paths in finding solutions. Global learners tend to learn in large jumps, absorbing material almost randomly without seeing connections until they can see the inter-relationships. They can solve complex problems quickly but they may have difficulty explaining how they did it.

The FelderSilverman class, which is a subclass of the LearningStyleCategory class, presents these dimensions through their related subclasses.

The acronym VARK stands for Visual, Aural, Read/write and Kinesthetic sensory modalities that are used for learning information. The VARK Learning model does not influence the sequence or structure of learning material. It only influences the nature and form of the delivered learning material. The learner's VARK preferences are determined using a questionnaire. The small part of this questionnaire is shown in Fig 2.

In the proposed ontology, the Vark class is defined as a subclass of the LearningStyleCategory class which represents these categories. The property learningCategoryValue is defined to represent the percentage score of a specific learner in each category.

The proposed ontology enables learners to determine their learning style based on different learning models. Consequently, personalisation is achievable in different ways. For example, if the learner selects VARK model, the content will be personalised based on the type of delivered content. However, if he/she selects FelderSilverman model, this will have effect on the sequence or structure of learning content. 


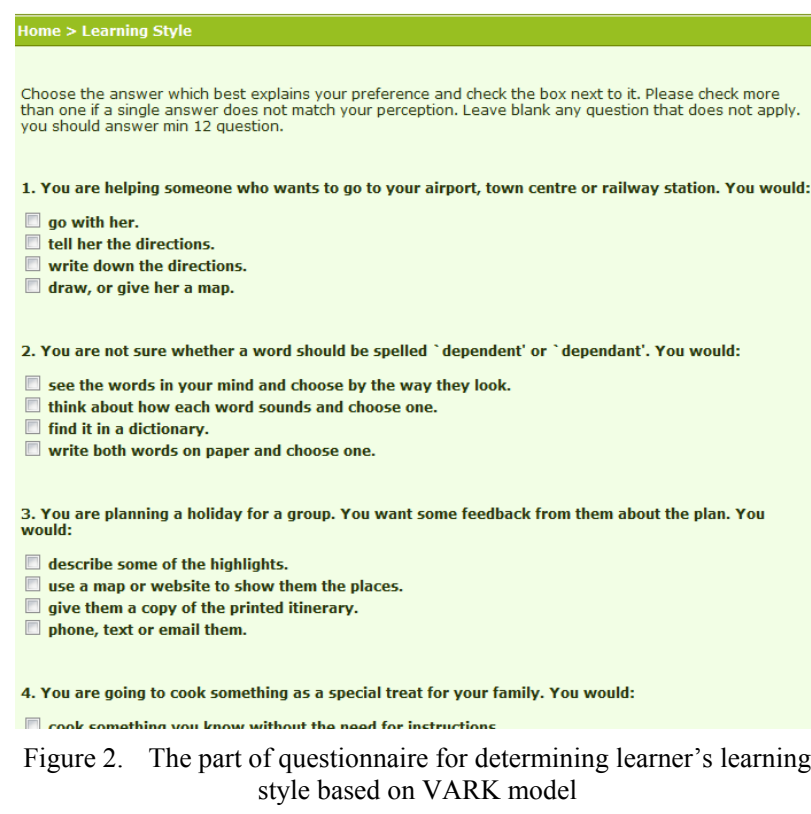

\section{ESTIMATION OF LEARNER's ABILITY}

Item response theory (IRT) is a model-based approach to select the most appropriate testing items based on the mathematical relationship between learner's abilities and item responses. The main purpose of IRT is to estimate a learner's ability or proficiency according to his/her responses to test items. The ideas of item response theory are based on the assumption that the probability of a correct answer to an item is a mathematical function of learner's ability and item variables. The item variable is referred to as the item difficulty, item discrimination, and the effect of random guessing.

To estimate a learner's ability, the item response theory uses different characteristic functions (Baker, 2001; Wang, 2006). In this paper, the item characteristic function with a three parameter is used to model each item in the test. The equation for this model is given by the following formula:

$$
P_{i}(\theta)=c_{i}+\left(1+c_{i}\right) \frac{1}{1+\exp \left(-a_{i}\left(\theta-b_{i}\right)\right)}
$$

\section{Where:}

$\theta$ is the ability level of learner

$\mathrm{a}_{\mathrm{i}}$ is the discrimination degree of item $\mathrm{i}$ is a constant 1.702

$b_{i}$ is the difficulty parameter of item $i$

$c_{i}$ is the guess degree of item $i$

$\mathrm{P}\left(\theta_{\mathrm{i}}\right)$ is the probability that learner with ability $\theta$ can response correctly to the item $\mathrm{i}$.

In order to estimate the ability of the learner, an unknown value, we can assume that all the numerical parameters of the items in the activity are known. The direct result is that the scale of the measurement is the same as the scale of the parameters in the items. After doing the item and receiving the response of the learner to all items of that activity, the items are dichotomously scored. This means that the learner gets one for the correct answer and zero for the incorrect answer. Hence, we will have a response pattern $\left(\mathrm{U}_{1}, \mathrm{U}_{2}, \mathrm{U}_{3}, \ldots ., \mathrm{U}_{\mathrm{j}}, \ldots ., \mathrm{U}_{\mathrm{n}}\right)$ which is called activity response vector, where $\mathrm{U}_{\mathrm{j}}=1$ represents a correct answer given by the learner for the $\mathrm{j}^{\text {th }}$ item in the activity. On the contrary, $\mathrm{U}_{\mathrm{j}}=0$ represents an incorrect answer given by the learner for the $\mathrm{j}^{\text {th }}$ item in the activity. After that, the Maximum Likelihood Estimator (MLE) is applied to effectively estimate activity parameter and the learner's abilities (Hambleton et al 1991). Bock and Mislevy derived the quadrature form to estimate learner ability (Baker, 1992). This formula is as follows:

$$
\hat{\theta}=\frac{\sum_{k}^{q} \theta_{k} L\left(u_{1}, u_{2}, \ldots, u_{n} \mid \theta\right) A\left(\theta_{k}\right)}{\sum_{k}^{q} L\left(u_{1}, u_{2}, \ldots, u_{n} \mid \theta\right) A\left(\theta_{k}\right)}
$$

Where $\theta$ is the estimation of the ability of the learner $L\left(u 1, u_{2}, \ldots, u_{n} \mid \theta\right)$ is, the value of likelihood function and $\mathrm{A}(\theta)$ represents the quadrature weight at a level below the learner's ability. The likelihood function has been calculated as follows:

$$
L\left(\theta \mid u_{1}, u_{2}, \ldots, u_{n}\right)=\prod_{i=1}^{n} P(\theta)^{u 1} Q(\theta)^{(1-u 1)}
$$

Where $\operatorname{Pi}(\theta)$ denotes the probability that a learner responds correctly to the $i^{\text {th }}$ item at a level below ability level $\theta$ and $\mathrm{Qi}(\theta)=1-\mathrm{P}_{\mathrm{i}}(\theta)$ represents the probability that the learner responds incorrectly to the $i^{\text {th }}$ item at a level below the ability level $\theta, \mathrm{u}_{\mathrm{i}}=1$ if the answer of $\mathrm{i}^{\text {th }}$ is correct and $\mathrm{u}_{\mathrm{i}}=0$ if the answer of $\mathrm{i}^{\text {th }}$ is incorrect (Chen \& Chung, 2008). The user ability profile is updated based on activity results learned from the item response theory.

\section{USING LEARNER MODEL FOR PERSONALISATION IN ONTO-PADEL}

One of the technical aims of adaptive learning is to personalise learning according to learner's needs. To achieve this goal, e-learning systems should have sufficient information about learners. Two of the most important information which can be helpful to promote personalisation, is the learner's abilities and knowledge about the subject domain, which can be obtained through assessments. In onto-PAdel, we use tests to assess learner's knowledge about each topic in the domain. As we explained in detail in the previous sections, the result of tests are analysed according to IRT to estimate learner's abilities. If the student fails to answer a test correctly, the system provides him/her with an alternative learning path, i.e., it suggests learning content with lower difficulty level, or it suggests reading prerequisite topic(s) that the student needs in order to get better results. Learners always have the option for accepting system's recommendations or to move onto the next topic. Furthermore, new learner's abilities and knowledge level are updated dynamically throughout the learning steps in order to adapt the learning material to the learner's updated features in the next level.

Moreover, the system uses other information from the learner model (e.g. learning style, preferences and feedback) to perform the adaptation of the learning material 
and provides adaptive presentation and navigation support to the learner. For instance, learning styles are typically defined as the way people prefer to learn. For example some students prefer to learn through activities while others prefer to learn by reading. The learning style is one of the stable characteristics of a learner that do not change during a learning session. Therefore, in the registration period, the learner's learning style is inferred through filling relevant questionnaires, and then during the learning process, the corresponding teaching strategy is taken into account in order to present suitable content.

\section{CONCLUSION}

In this paper, we presented learner's model ontology as one of the main ontologies needed to create personalised content for individual learners. The ontology is designed to represent learner's learning styles, prior knowledge, ability and preferences. The proposed ontology is able to represent different learning style models such as Kolb, Felder-Silverman and VARK. It enables learner to determine his/her learning style based on different models. The response of the learner to some regular tests during the learning process is analysed by the IRT and the ability of the learners is evaluated. The system recognises the changes in the learner's level of knowledge as they progress. Accordingly, the learner model is updated based on the learner's progress and abilities. Consequently, the passage from one stage of the learning process to the next is determined based on the updated learner's profile.

\section{REFERENCES}

[1] Baishuang, Q., \& Wei, Z. (2009). Student Model in Adaptive Learning System Based on Semantic Web. Paper presented at the Proceedings of the 2009 First International Workshop on Education Technology and Computer Science - Volume 02. http://dx.doi.org/10.1109/ETCS.2009.466

[2] Baker, F. B. (1992). Item Response theory: Parameter estimation techniques. New York: Marcel Dekker.

[3] Baker, F. B. (2001). The basics of item response theory (second ed.). Washington: ERIC clearing house on assessment and evaluation.

[4] Baylari, A., \& Montazer, G. A. (2009). Design a personalized elearning system based on item response theory and artificial neural network approach. Expert Systems with Applications, 36(4), 80138021. doi: 10.1016/j.eswa.2008.10.080 http://dx.doi.org/10.1016/ j.eswa.2008.10.080

[5] Brusilovsky, P., Sosnovsky, S., \& Yudelson, M. (2005). Ontologybased framework for user model interoperability in distributed learning environments Paper presented at the Proceedings of World Conference on ELearning ( E-Learn 2005), Vancouver, Canada.

[6] Brut, M., Asandului, L., \& Grigora, G. (2009). A Rule-Based Approach for Developing a Competency-Oriented User Model for E-Learning Systems. Paper presented at the Internet and Web Applications and Services, 2009. ICIW '09. Fourth International Conference on Venice/Mestre.

[7] Bunt, A., \& Conati, C. (2003). Probabilistic Student Modelling to Improve Exploratory Behaviour. User Modeling and UserAdapted Interaction, 13(3), 269-309. http://dx.doi.org/10.1023/ A: 1024733008280

[8] Chen, C.-M., \& Chung, C.-J. (2008). Personalized mobile English vocabulary learning system based on item response theory and learning memory cycle. Computers \& Education 51(2), 624-647. http://dx.doi.org/10.1016/j.compedu.2007.06.011

[9] Conati, C., Gertner, A., \& Vanlehn, K. (2002). Using Bayesian Networks to Manage Uncertainty in Student Modeling. User Modeling and User-Adapted Interaction, 12(4), 371-417. http://dx.doi.org/10.1023/A:1021258506583
[10] Díaz, A., \& Gervás, P. (2005). Personalisation in news delivery systems: Item summarization and multi-tier item selection using relevance feedback. Web Intelli. and Agent Sys., 3(3), 135-154.

[11] Dolog, P., \& Schäfer, M. (2005). A framework for browsing, manipulating and maintaining interoperable learner profiles. Paper presented at the Proceedings of the 10th international conference on User Modeling, Edinburgh, UK.

[12] Felder, R. M., \& Silverman, L. K. (1988). Learning and Teaching Styles In Engineering Education. English Education, 78(7), 674681

[13] Felder, R. M., \& Soloman, B. A. (1991). The Index of Learning Styles ${ }^{\circledR} \quad$ (ILS) Retrieved 11/09/2011, 2011, from http://www.engr.ncsu.edu/learningstyles/ilsweb.html

[14] Fleming, N. D., \& Mills, C. (1992). Not Another Inventory, Rather a Catalyst for Reflection. To Improve the Academy, 11, 137-146.

[15] Gauch, S., Speretta, M., Chandramouli, A., \& Micarelli, A. (2007). User profiles for personalized information access. In B. Peter, K. Alfred \& N. Wolfgang (Eds.), The adaptive web (pp. 5489): Springer-Verlag. http://dx.doi.org/10.1007/978-3-540-72079$\underline{9} 2$

[16] Gruber, T. R. (1993). A translation approach to portable ontology specification Knowledge Acquisition, 5(2), 199-220. http://dx.doi.org/10.1006/knac.1993.1008

[17] Henze, N., Dolog, P., \& Nejdl, W. (2004). Reasoning and Ontologies for Personalized E-Learning in the Semantic Web. Educational Technology \& Society, 7(4), 82-97.

[18] Honey, P., \& Mumford, A. (1986). Using Your Learning Styles Maidenhead, UK: Peter Honey.

[19] Jeong, H.-Y., Choi, C.-R., \& Song, Y.-J. (2012). Personalized Learning Course Planner with E-learning DSS using user profile. Expert Systems with Applications, 39(3), 2567-2577. http://dx.doi.org/10.1016/j.eswa.2011.08.109

[20] Jeremic', Z., Jovanovic', J., \& b, D. G. (2012). Student modeling and assessment in intelligent tutoring of software patterns. Expert Syst. Appl., 39(1), 210-222. http://dx.doi.org/10.1016/j.eswa.2011 .07 .010

[21] Jovanović, J., Gašević, D., \& Devedžić, V. (2009). TANGRAM for Personalized Learning Using the Semantic Web Technologies. Journal of Emerging Technologies in Web Intelligence, 1(1), 6-21. http://dx.doi.org/10.4304/jetwi.1.1.6-21

[22] Klasnja-Milicevic, A., Vesin, B., Ivanovic, M., \& Budimac, Z. (2010). E-learning personalization based on hybrid recommendation strategy and learning style identification. Computers \& Education, 56(3), 885-899. http://dx.doi.org/ 10.1016/j.compedu.2010.11.001

[23] Kolb, D. A. (1984). Experiential learning: experience as the source of learning and development. United State of America: Prentice Hall, Inc.

[24] Liu, Z., Liu, L., Kang, H., Zhong, S., \& Jia, B. (2009). An Ontology-Based Method of Adaptive Learning. Paper presented at the Proceedings of the 2009 Fifth International Joint Conference on INC, IMS and IDC.

[25] Lu, M. (2008). Effectiveness of vocabulary learning via mobile phone. Journal of Computer Assisted Learning, 24(6), 515-525. http://dx.doi.org/10.1111/j.1365-2729.2008.00289.x

[26] Snae, C., \& Brueckner, M. (2007). Ontology-driven e-learning system based on roles and activities for Thai learning environment Interdisciplinary Journal of E-Learning and Learning Objects, 3, $1-17$.

[27] Surjono, H. D. (2011). The Design of Adaptive E-Learning System based on Student's Learning Styles. International Journal of Computer Science and Information Technologies, 5(2), 23502353.

[28] Vesin, B., Ivanović, M., Klašnja-Milićević, A., \& Budimac, Z. (2011). Rule-Based Reasoning for Building Learner Model in Programming Tutoring System. In H. Leung, E. Popescu, Y. Cao, R. H. Lau \& W. Nejdl (Eds.), Advances in Web-Based Learning ICWL 2011 (Vol. 7048, pp. 154-163): Springer Berlin Heidelberg. http://dx.doi.org/10.1007/978-3-642-25813-8 17

[29] Wang, F.-H. (2006). Application of componential IRT model for diagnostic test in a standard conformant elearning system. Paper presented at the Sixth IEEE International Conference on 
PAPER

Towards an Ontological Learners’ Modelling APProACH FOR PERSONALISED E-LEARning

Advanced Learning Technologies. http://dx.doi.org/10.1109/ ICALT.2006.1652414

[30] Winter, M., Brooks, C., \& Greer, J. (2005). Towards Best Practices for Semantic Web Student Modelling. Paper presented at the Proceedings of the 2005 conference on Artificial Intelligence in Education: Supporting Learning through Intelligent and Socially Informed Technology.

[31] Yarandi, M., Tawil, A. R., \& Jahankhani, H. (2012). Ontologies for Personalised Adaptive Learning Paper presented at the Advances in Computing \& Technology 2012, London,Uk.

\section{AUTHORS}

Seyed Ali Hosseini is with King's College London, London, UK.

Abdel-Rahman H. Tawil, Hossein Jahankhani, and Maryam Yarandi are with University of East London, London, UK.

This article is an extended and modified version of a paper presented at the the Interactive Mobile and Computer Aided Learning (IMCL2012), held in November 2012, at Princess Sumaya University for Technology, Amman, Jordan. Received 9 January 2013. Published as resubmitted by the authors 25 April 2013 . 